\title{
PERANCANGAN MODEL BISNIS CINDERAMATA SEBAGAI IMPLEMENTASI SOCIAL ENTREPRENEURSHIP
}

\author{
Rifa'i $^{1}$, Muhammad Ridwan Andi Purnomo ${ }^{2}$, Taufiq Immawan ${ }^{3}$ \\ Magister Teknik Industri, Fakultas Teknologi Industri, Universitas Islam Indonesia. ${ }^{1,2,3)}$ \\ Jl. Kaliurang km. 14,5, Sleman Yogyakarta 55584 \\ E-mail:rifaifay3@gmail.com ${ }^{1}$,ridwan_ie@uii.ac.id ${ }^{2}$,985220101@uii.ac.id ${ }^{3}$
}

\begin{abstract}
Strategic location, near by national economic center, exposes Banten with positive vibe for its economic growth. Nevertheless, according to existing data, on the 3rd quarter in 2015, tourism sector only reached 2,6\% of market share. Thus, it hasn't been existed as featured sectors. It appears due to several reasons, one of them is supporting component for this cultural creative industry that still under-developed. One of the local creative industries that has purpose to promote the uniqueness value of Banten culture through local souvenirs is Ora Bae (OB). This business is built based on social entrepreneurship. OB was established in 2013. However, the designated business model, apparently do not consistent with the income.

Referring to above problem, therefore this research is conducted to identify and evaluate the existing business model as well as to design appropriate one. This research is carried out by implementing direct observation in Ora Bae Souvenir Shop and several Small and Middle Enterprises (SMEs) under it. The interview is performed by using SWOT concept that integrated with Business Model Canvas (BMC).

Later, the results of observation and interview are used as the current business model formula that will be employed for SWOT analysis. Its results will be applied as basic for determining the business model alternative. Blue Ocean Strategy is employed to eliminate elements of business model that are insignificant and to create innovation in the latest business model. The improvement conceptsare conducted by enhancing the numberscostume's designersto anticipate new customers' segmentation, neglecting low price components on offered price proposition, improving the products' distribution channel on places that potentially could maximize the available channelsby participating in Banten events as advertising service. The improvements are also supported by resources in IT Support. In maintaining the relationship with customers, it is required additional services such as personal assistance and customer care. The innovation of this recent business model is expected to be the alternative for solution on problems that encountered by Ora Bae brand.
\end{abstract}

Keywords : Social entrepreneurship, Business Model Canvas, SWOT analysis, Blue Ocean Strategy, Souvenir.

\section{PENDAHUluan}

Berdasarkan kajian ekonomi dan keuangan regional Provinsi Banten pada triwulan II tahun 2013 pertumbuhan investasi mencapai 17,62\%. Letak Banten yang strategis dekat dengan pusat perekonomian nasional memberikan dampak positif hingga tahun 2015. Lain halnya pada sektor pariwisata, dengan Jumlah Obyek Daya Tarik Wisata (ODTW) Banten berdasarkan data Induk Pengembangan Pariwisata Daerah (RIPPDA) tahun 2013 telah tercatat sebanyak 564 obyek wisata yang terbagi kedalam beberapa kategori yaitu: wisata marina, wisata sejarah, suaka alam, dan obyek wisata lainnya (DISBUDPAR, 2013). Namun hasil yang diperoleh menurut kajian ekonomi dan keuangan regional Provinsi Banten pada triwulan III tahun 2015 hanya mencapai pangsa 2,6\% sehingga sektor kepariwisataan belum menjadi sektor unggulan. Hal tersebut terkendala dalam komponen - komponen pendukung berupa sarana maupun prasarana dan industri kreatif bernuansa khas daerah setempat yang masih belum berkembang di Provinsi Banten (Setyawan, 2015). 
Untuk mengangkat perekonomian maka diperlukan pendekatan social entrepreneurship agar masyarakat dapat bergerak aktif. Menurut Wennekers, et al., (1999) mengungkapkan entrepreneurship merupakan kemauan yang nyata dari keinginan individu, diri sendiri, di tim, maupun didalam dan diluar organisasi yang ada untuk beberapa tujuan. pertama, memahami dan menciptakan peluang baru pada ekonomi (produk baru, metode produksi baru, skema atau struktur organisasi baru dan kombinasi produk market baru). Kedua, memperkenalkan gagasan atau ide baru di pasar dalam menghadapi suasana ketidak pastian dan hambatan lain yang terjadi, dengan membuat keputusan tentang lokasi, bentuk dan penggunaan sumber daya dan lembaga. Dan Social entrepreneurship didefinisikan sebagai proses menghargai unsur budaya tradisional dan menghilangkan cara ekonomi lama yang mengganggu dalam status ekonomi dengan melalui proses yang kreatif, mengembangkan kombinasi baru dari sumber daya yang memungkinkan untuk inovasi sosial, ekonomi, lingkungan, perubahan, dan evolusi (Curry, et al., 2016).

Salah satu perusahaan industri kreatif dibidang cinderamata Banten yang mengangkat kepariwisataan berbasis social entrepreneurship bersama penggiat Usaha Kecil Menengah (UKM) yaitu Ore Bae (OB). OB dirintis sejak pertengahan tahun 2013, produk yang dimiliki meliputi souvenir dan cinderamata berupa pakaian kaos, miniatur menara Banten, gantungan kunci yang berbahan dasar limbah kayu, kain tenun Baduy serta kerajinan khas Baduy. Dari setiap produk yang diproduksi memiliki nilai - nilai kekhasan daerah Banten. Namun hingga saat ini, bisnis model yang dijalankannya masih belum sesuai terhadap kondisi sekarang. Berdasarkan fenomena tersebut maka perlu dilakukan identifikasi dan evaluasi atas model bisnis yang berjalan saat ini serta merancang model bisnis yang tepat sesuai kondisi sekarang.
Bisnis model merupakan suatu hipotesis bagaimana perusahaan mampu menghasilkan pendapatan dalam jangka panjang, apa yang dijualkannya, kepada siapa barang tersebut dijual, bagaimana cara mengumpulkan pendapatannya, teknologi apa yang akan digunakan, kapan perusahaan bergantung pada mitra bisnisnya serta bagaimana dengan hal biaya (Trimi \& Berbegal-Mirabent, 2012). Terdapat beberapa tools yang dapat mengidentivikasi dan mengevaluasi dari bisnis model perusahaan yang berjalan, salah satunya Business Model Canvas (BMC). $\mathrm{BMC}$ adalah template manajemen strategis untuk mengembangkan sistem baru atau mendokumentasikan model bisnis yang sudah ada (Xing \& Ness, 2016). BMC terdiri dari sembilan blok diagram yang dapat mengevaluasi, memberikan solusi dan memecahkan permasalahan - permasalahan kompleks yang dihadapi perusahaan menjadi sederhana baik didalam proposisi nilai, infrastruktur, pelanggan dan keuangan.

Dalam uraian diatas maka penulis tertarik untuk melakukan penelitian dengan menggunkana $\mathrm{BMC}$ pada perusahaan $\mathrm{OB}$ sebagai identifikasi dan evaluasi terhadap model bisnis yang sedang berjalan. Hasil dari identifikasi tersebut digunakan sebagai bahan dasar untuk merumuskan model bisnis yang terjadi sekarang. Adapun bentuk informasi yang akan digali mencakup pada sembilan blok Business Model Canvas (BMC). Hasil dari indentifikasi BMC digunakan sebagai analisis SWOT yang berfungsi untuk membandingkan antara kekuatan, kelemahan, peluang, serta ancaman yang akan diterima oleh perusahaan.

Pengkombinasian analisis SWOT dan BMC memungkinkan penilaian yang terfokus dan evaluasi terhadap model bisnis perusahaan serta elemen - elemennya (Tjitradi, 2015). Hasil dari analisis SWOT kemudian dijadikan formula untuk melakukan perubahan atas model sistem yang berjalan saat ini. Adapun penggunaan blue ocean strategy digunakan untuk mengeliminasi elemen - elemen model bisnis 
yang tidak sesuai dan menciptakan inovasi model bisnis yang terbaru.

\subsection{Cinderamata}

Cindermata sudah ada dari ribuan tahun yang lalu dan selalu ada selama sesorang melakukan perjalanan, karena cindermata merupakan elemen penting dari pengalaman (Swanson \& Timothy, 2012). Menurut Immaniar dan Ningrum (2014), Cinderamata adalah sebuah benda yang berbentuk dua dimensi atau tiga dimensi yang diberikan oleh pihak terkait (lembaga, instansi atau perorangan) kepada penerima atau masyarakat pada event - event tertentu sebagai tanda mata atau kenang - kenangan agar dapat mengenang kembali kejadiankejadian yang telah terjadi. Kebiasaan inilah yang menjadi budaya bagi para wisatawan yang berkunjung ke suatu obyek wisata yang dituju, belum lengkap rasanya jika tidak membawa kenang - kenangan khas daerah tersebut sebagai buah tangan ke daerah asal. Cinderamata biasanya dibawa sebagai oleholeh atau kenang - kenangan yang mencerminkan atas keindahan dan kekhasan daerah yang dituju dan biasa dibawa oleh para wisatawan pada saat kembali ke tempat asalnya (Gunardi, 2010)

Paraskevaidis dan Andriotis (2015) mengungkapkan mengenai nilai yang terkandung dan alasan utama membeli cindermata adalah sebagai berikut :

1. Sebagai nilai pengingat situs atau history selama melakukan perjalanan dan untuk mengurangi utilitarian.

2. Sebagai nilai tukar kenang kenangan dari pemberian seseorang.

3. Sebagai prestise dan status sosial juga berpengaruh dalam pembelian cinderamata.

4. Spiritual - nilai, hal tersebut biasanya didasarkan pada agama dan praktek di suku-suku primitif atau pedalaman dan terus eksis melekat dimasyarakat moderen.
Perkembangan cinderamata saat ini haruslah melupakan konsep yang bertema SSS (Sea, Sun, Sand) dalam penjualan cinderamata, maupun souvenir otentik yang berlandasan harga murah. Melainkan harus lebih merangkap atau melirik ke konsep EEE (Education, Excitement, Entertainment) yang mengekspresikan kebutuhan otentik dan souvenir yang mengandung sejarah asli (Jurič \& Vuković, 2010). Selain itu, keaslian produk dari cinderamata dalam satu daerah wisata harus dijaga (Trinh, et al., 2014). Untuk menjaga keaslian cinderamata tersebut tidak lepas peran aktif dari pedagang ritel yang langsung bersentuhan dengan konsumen wisatawan dan pemasok (suplier).

\subsection{Entrepreneurship}

Seiring perkembangan waktu, entrepreneurship semakin berkembang dari sisi aktivitas maupun lingkup aktivitasnya sendiri. Pada awal dikemukannya oleh Schumpeter (1934) entrepreneurship merupakan sebuah penggabungan aktivitas dari berbagai elemen sehingga menghasilkan konsep kombinasi baru untuk terciptanya produk baru yang konsumen belum familier atau kualitas baru yang baik, pengenalan metode produksi baru, pembukaan pangsa pasar yang baru, sumber daya baru (bahan baku mentah / setengah jadi), dan melaksanakan organisasi baru dibidang perindustrian. Sulistyo dan Siyamtinah (2016) mengungkapkan bahwa entrepreneurship merupakan proses dinamis seseorang untuk menciptakan suatu kekayaan intelektual, dimana kekayaan intelektual tersebut memiliki resiko utama baik dari modal, waktu dan komitmen pada profesi dalam hal menciptakan nilai produk atau layanan. Negara yang maju adalah negara yang memberikan peluang besar pada kebebasan ekonom terhadap penduduknya. Dimana kebebasan tersebut memberikan ruang entrepreneurship untuk terus bergerak di perusahaan yang dikelola agar roda perekonomian negara selalu bergerak maju (Angulo-Guerrero, et al. 2017). 


\subsection{Business Model Canvas (BMC)}

Business Model Canvas adalah sebuah alat bantu untuk mempermudah dalam penyeselaian masalah dengan cara menggambarkan, menvisualisasikan, menilai dan mengubah model bisnis kompleks menjadi sederhana. Konsep ini ditampilkan dalam satu lembar kanvas yang berisi peta sembilan blok dasar yang menunjukkan logika berpikir. Bagaimana bisnis dapat berjalan sesuai harapan dan menghasilkan pendapatan dengan mempertimbangkan komponen - komponen apa saja yang dibutuhkan untuk perencanaan sebuah model bisnis. Adapun komponen sembilan blok pada model bisnis kanvas adalah segmen pelanggan (CS), proposisi nilai (VP), saluran $(\mathrm{CH})$, hubungan pelanggan (CR), arus pendapatan (RS), sumber daya utama (KR), aktifitas utama (KA), bangunan kemitraan (KP) dan struktur biaya (CS) (Osterwalder, at al., 2010). Semuanya tergambar pada gambar 1 .

Dengan berkembangnya waktu, pengetahuan selalu berkembang. Beberapa penelitain yang meneliti dengan menggunakan Business Model Canvas (BMC) adalah: Trimi dan Berbegal-Mirabent
(2012) melakukan penelitian tentang pentingnya desain model bisnis sebagai tugas utama bagi pengusaha dalam proses memulai usaha berbasis teknologi serta memajukan pemahaman tentang perkembangan dalam desain model bisnis dalam bidang kewirausahaan.Hasil yang diperoleh dari penelitian tersebut adalah perlunya merancang model bisnis yang fleksibel yang memungkinkan perusahaan untuk merubah ulang bentuk pilihan strategi secara efisien yang menguraikan logika bisnis sesuai dengan tuntutan pasar yang berkembang. Gabriel, et al. (2016) menggunakan BMC untuk menganalisis bisnis pengusaha dibidang energi yang terbarukan dengan menilai jenis usaha yang saling berkaitan disetiap kondisi negara untuk menilai dampak dari perbedaan disetiap regional. Temuan yang diperoleh menunjukkan bahwa berbagai wilayah dapat mendukung model bisnis tertentu lebih banyak dari pada yang lain, karena perbedaan tingkat kepentingan pemerintah terhadap energi terbarukan, tata kelola dan dukungan kebijakan yang relatif mudah melakukan bisnis.

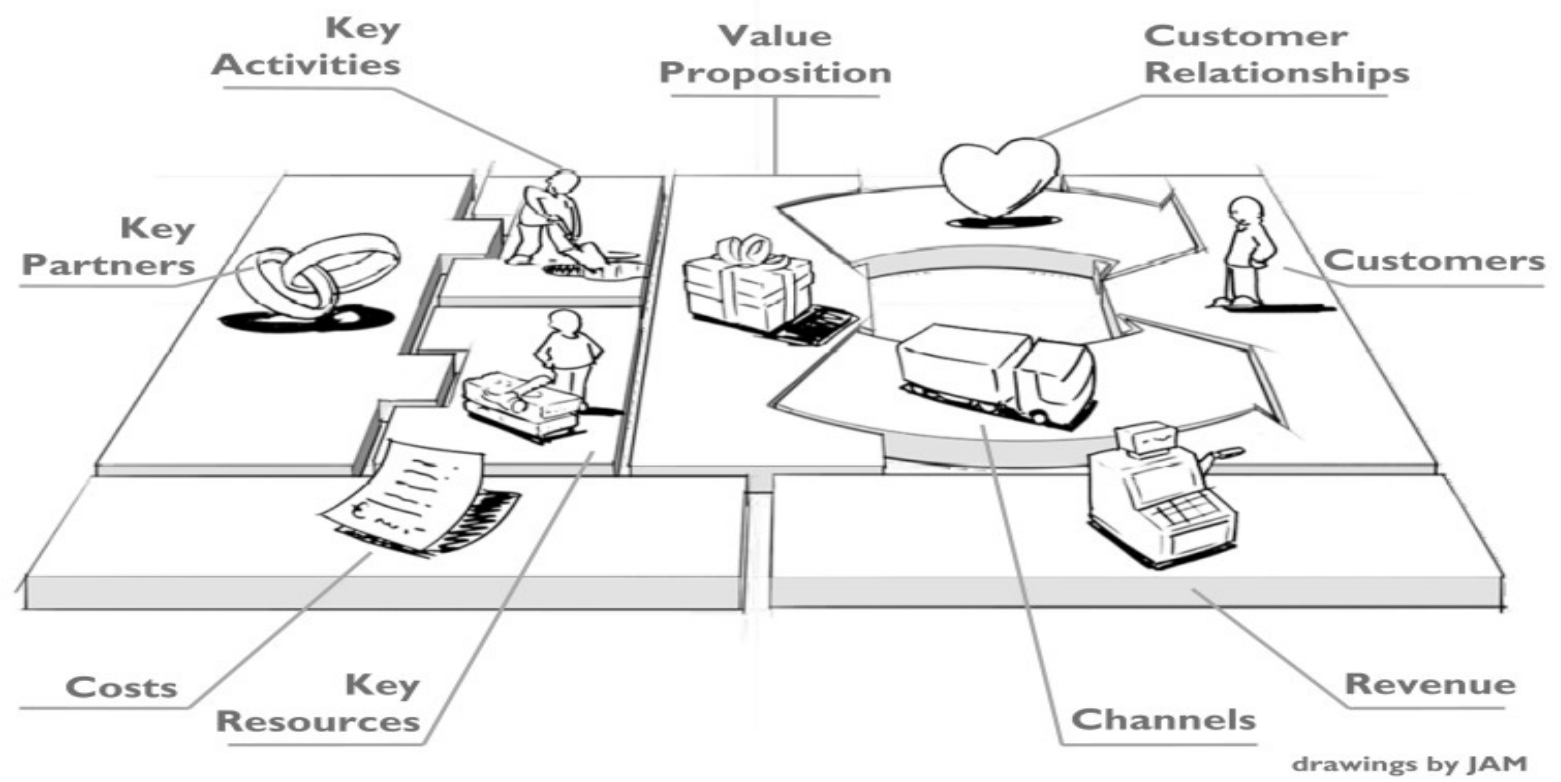

Gambar 1. Sembilan Blok Model Bisnis Kanvas.

(Sumber :https://espriex.co/business-model-canvas) 
Mlecnik, et al. (2012) melakukan penelitian menggunakan kerangka proyek one stop shop dan BMC untuk mengidentifikasi dan mengembangkan peluang kerjasama bersama UKM untuk renovasi perumahan maju di Belgia, Denmark, Finlandia dan Norwegia. Hasil yang diperoleh bahwa bisnis baru terkait dengan proses inovasi dari renovasi rumah adalah pemilik rumah tidak terbebani atas layanan yang ditawarkan. Díaz-Díaz, et al. (2017) menggunakan pendekatan BMC pada kerangka non profits dalam mendesain model bisnis pelayanan publik yang beroperasi di ekosistem kota pintar. Hasil yang diperoleh bahwa alat manajemen ini telah terbukti berguna untuk menggambarkan model bisnis dikota - kota pintar karena memungkinkan untuk mengidentifikasi aspek - aspek penting, seperti masalah sosial dan lingkungan, dimana kerangka lain tidak memperhitungkan. Martikainen, et al. (2014) melakukan penelitian dengan membangun model bisnis yang potensial untuk penyedia layanan logistik yang beroperasi di rantai suplai makanan lokal, dimana kebutuhan layanan logistik yang saling berbeda. Hasil yang diperoleh dalam penelitiannya bahwa, pendekatan yang dilakukan dapat membangun koneksi yang logis antara layanan yang ditawarkan dan fundaments bisnis penyedia layanan logistik. Ellizabeth Cindy Tjitradi melakukan penelitian dengan evaluasi atas model bisnis yang sedang dijalankan serta merancangkan model bisnis yang tepat dengan menggunakan pendekatan sembilan elemen pada Business Model Canvas (BMC) diperusahaan Sulis Cake.

\subsection{Analisis SWOT}

Analisis SWOT adalah alat untuk mengidentifikasi faktor - faktor yang berpengaruh dalam perusahaan untuk merumuskan strateginya. Analisa ini berlandaskan logika yang memaksimalkan kekuatan (Strengths) dan peluang (Opportunities), namun secara bersamaan dapat meminimalisir kelemahan (Weaknesses) dan ancaman (Threats) pada perusahaan (Rangkuti, 1997). Penelitian yang dilakukan oleh Osterwalder, at al.,(2010) yaitu menggabungkan Analisis SWOT dengan Business Model Canvas dengan tujuan untuk menilai dan mengevaluasi terhadap model bisnis perusahaan terhadap blok di setiap bangunannya. Adapun gambarannya sebagai berikut :

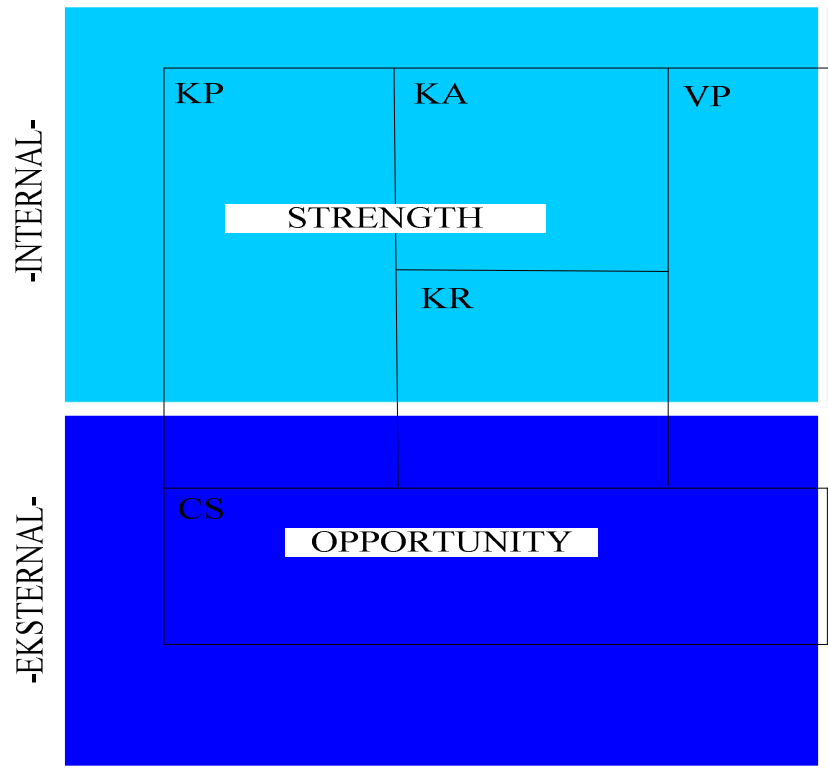

-SANGAT MEMBANTU-
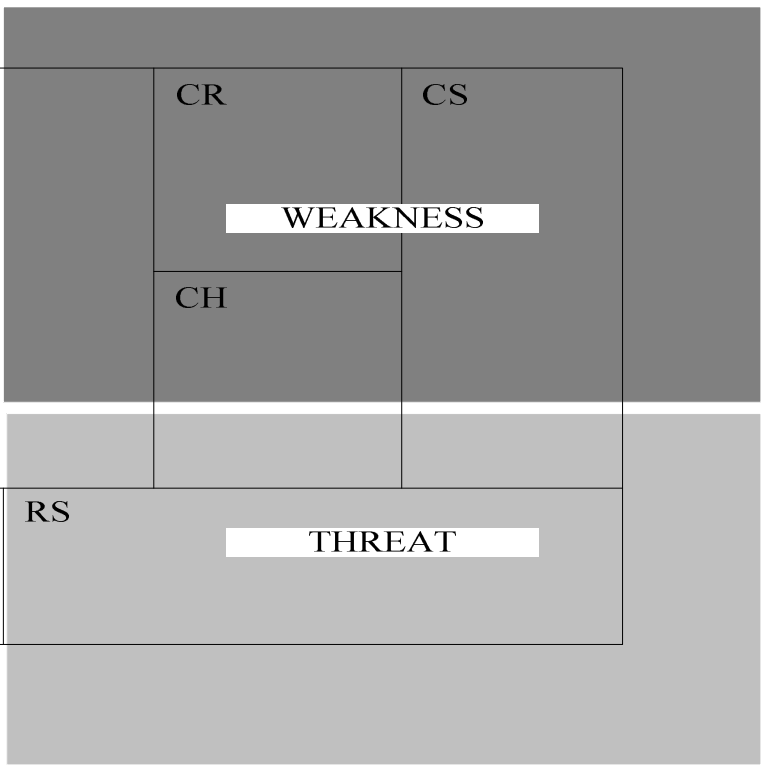

-SANGAT MEMBAHAYAKAN-

Gambar 2. SWOT dalam BMC.

(Sumber: Business Model Generation, 2015) 


\subsection{Blue Ocean Strategy}

Blue Ocean Strategy (BOS) merupakan bagian dari dunia bisnis dimasa sekarang dan masa lalu yang selalu berkembang. Blue Ocean Strategy (BOS) muncul karena ketatnya persaingan di Red Ocean Strategy (ROS). Banyaknya pesaing yang selalu berkembang dan tumbuh disetiap waktunya mengakibatkan perusahaan dituntut untuk selalau berinovasi dan memunculkan produk - produk yang terbaru serta unggul dari pesaing - pesaingnya. Kim dan Mauborgne (2005) mengungkapkan, bahwa perlunya inovasi nilai dalam penciptaan ruang pasar baru. Inovasi nilai tersebut berarti meningkatkan nilai untuk pelanggan dengan menciptakan layanan dan manfaat baru, sementara secara bersamaan mengurangi biaya dengan menghilangkan layanan dan fitur yang kurang memiliki nilai. Adapun gambaran inovasi nilai tersebut dapat dilihat pada gambar 3 .

Dalam mencapai inovasi nilai tersebut maka digunakan kerangka kerja empat langkah. Kerangka kerja empat langkah tersebut meliputi peningkatan, penciptaan, pengurangan dan penghapusan. Osterwalder et al., (2010) mengungkapkan dengan memadukan konsep inovasi nilai dan kerangka kerja empat langkah beserta Business Model Canvas maka akan menciptakan alat bantu baru yang sangat tepat dalam menciptakan sebuah model bisnis. Adapun hal tersebut dapat dilihat dalam gambar 4.

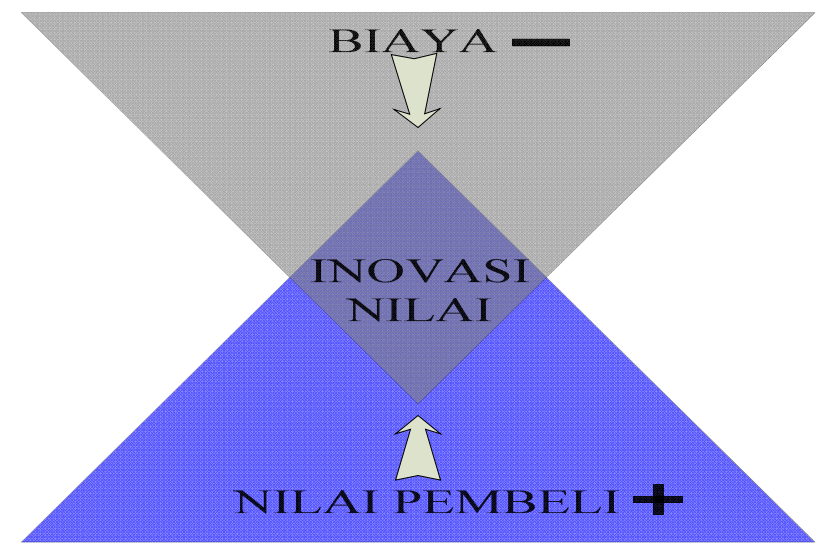

Gambar 3. Inovasi Nilai.
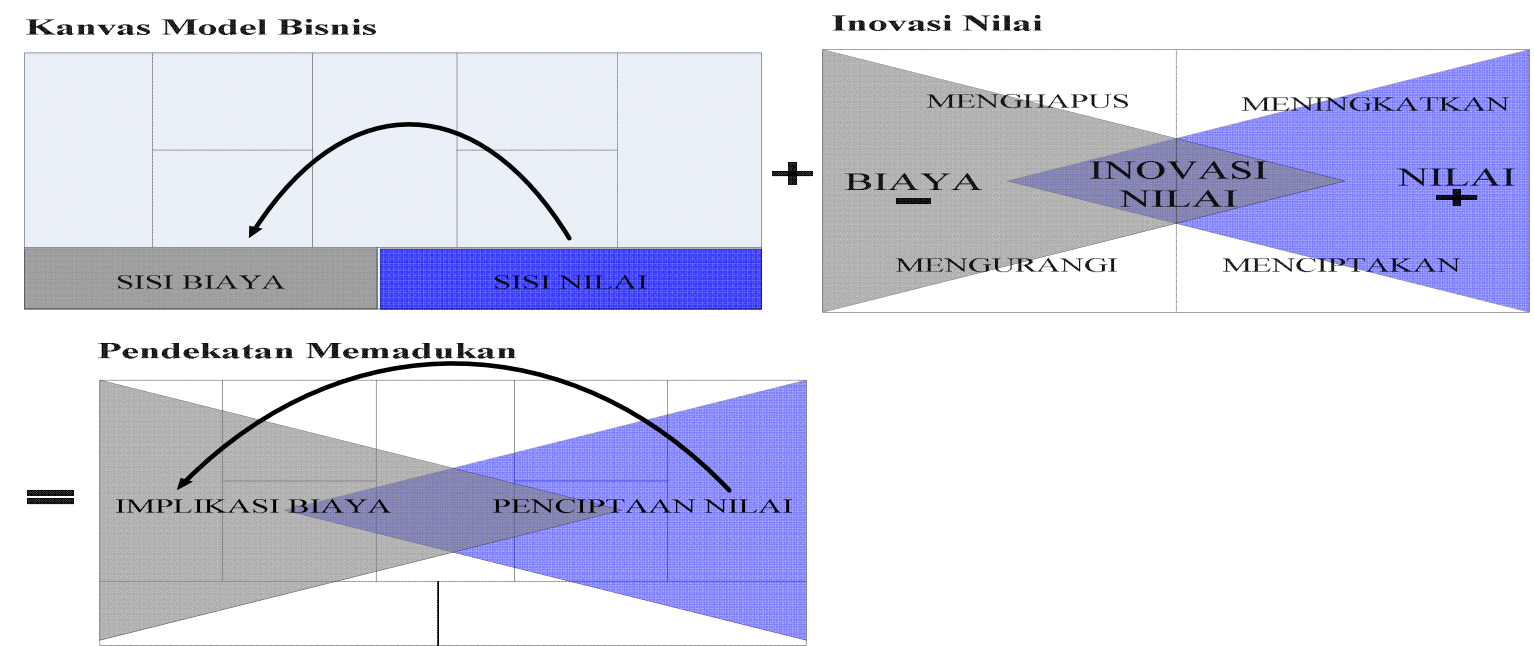

Gambar 4. Kerangka Kerja BOS dengan BMC.

(Sumber: Business Model Generation, 2015) 


\section{METODOLOGI PENELITIAN}

\subsection{Jenis Penelitian}

Penelitian ini dilakukan bersifat kualitatif dan deskriptif. Didalam penelitain ini penulis akan melakukan evaluasi dan perancangan model bisnis OB yang akan datang dengan pendekatan BMC.

\subsection{Obyek Penelitian}

Obyek penelitian ini adalah Souvenir dan Cinderamata Banten brand "Ore Bae (OB)".

\subsection{Pengidentifikasi Masalah}

Subyek penelitian dalam penulisan ini adalah pemilik dan konsumen Cinderamata Banten brand "Ore Bae (OB). Subyek penelitian ini penulis tujukan untuk memberikan informasi atas data yang bersangkutan dengan proses penelitian.

Obyek penelitian dilakukan di Souvenir dan Cinderamata Banten brand "Ore Bae (OB)". Penelitian dilakukan pada aspek perancangan model bisnis yang sedang berjalan serta merancang model bisnis Souvenir dan Cinderamata Banten khususnya pada brand "OB" dengan tepat.

\subsection{Landasan Teori}

Landasan teori ini disusun berdasarkan gambaran umum bisnis cinderamata dengan memperhatikan fenomena model bisnis yang sedang berjalan.

\subsection{Pengumpulan Data}

Pengerjaan penelitian ini menggunakan data kualitatif yang bersumber dari data primer dan data sekunder. Data sekunder diperoleh dari laporan keuangan per triwulan dari Bank Indonesia dan total kunjungan wisata per tahunan dari Dinas Budaya dan Pariwisata Provinsi Banten. Data primer dalam penelitian ini diperoleh dari pemiliik, klien dan konsumen Souvenir dan Cinderamata Banten brand "Ore Bae (OB)" dengan teknik observasi dan wawancara.

Berikut metode pengumpulan data primer dalam pembuatan rencana model bisnis baru ini :
1) Observasi

Observasi atau pengamatan langsung dilakukan di Souvenir dan Cinderamata Banten brand "Ore Bae (OB)" mengenai bisnis model yang berjalan saat ini. adapun bagian yang diobservasi menyangkut tentang segmen pelanggan (CS), proposisi nilai (VP), saluran $(\mathrm{CH})$, hubungan pelanggan (CR), arus pendapatan (RS), sumber daya utama (KR), aktifitas utama (KA), bangunan kemitraan (KP) dan struktur biaya (CS).

2) Wawancara dengan pelaku usaha.

Proses wawancara dilakukan pada pemilik OB yang disesuaikan dengan pedoman konsep SWOT dari Osterwalder et al., (2010). Wawancara yang dimaksudkan untuk mengetahui informasi gambaran mengenai industri souvenir dan cinderamata meliputi beberapa hal seperti: pertumbuhan industri, kondisi persaingan, dan prospek bisnis ini dalam jangka panjang.

\subsection{Penentuan Teknik Sampling}

Teknik sampling dalam penentuan narasumber dalam penelitian ini, penulis menggunakan metode purposive sampling karena penulis sudah mengetahui pemegang informasi - informasi yang akurat. Jika pada prosesnya kurang lengkap penulis menggunakan snowball sampling untuk melengkapi kekurangan - kekurangan informasi yang diketahui narasumber. Narasumber dalam penelitian ini adalah pemilik OB. Selain itu juga penulis akan mewawancarai dengan usaha sejenis dengan OB, klien dan konsumen OB untuk kelengkapan data yang dibutuhkan.

\subsection{Uji Validitas Data}

Metode yang digunakan untuk uji validitas data penulis menggunakan metode triangulasi. Adapun macam triangulasi yang digunakan yaitu triangulasi sumber. Dimana dengan metode ini penulis memadukan tiga informasi yang diterima yaitu informasi dari hasil observasi, wawancara, dan dokumentasi. 


\subsection{Pengolahan dan Analisis Data}

Tahapan pengolahan dan analaisis data yang akan dilakukan penulis terbagi menjadi empat tahap. Tahap pertama, merumuskan permasalahan social entrepreneurship yang terjadi pada usaha cindermata brand OB. Tahap kedua, mengidentifikasi dan menganalisis terhadap kondisi sistem yang berjalan. Hasil dari identifikasi dan analisis akan digunakan sebagai bahan dasar untuk merumuskan model bisnis yang terjadi. Adapun bentuk informasi yang akan digali mencakup pada sembilan blok Business Model Canvas (BMC). Tahap ketiga, menganalisa permasalahan serta penilaian terhadap bisnis yang terjadi ditinjau dari berbagai aspek dengan menggunakan analisis SWOT dan dipadukan dengan Canvas Model (Osterwalder \& Pigneur, 2015). Tahap keempat, melakukan evaluasi dengan strategi blue ocean yang di kombinasikan dengan Canvas Model (Osterwalder \& Pigneur, 2015) untuk terciptanya model inovasi bisnis yang terbaru dan melakukan perbaikan pada sistem yang diaplikasikan sekarang. Tahap kelima, Memformulasikan model bisnis yang terbaru sebagai implementasi untuk peningkatan performa pada brand $\mathrm{OB}$.

\section{HASIL DAN PEMBAHASAN}

Pada bagian ini akan dijelaskan hasil dari identifikasi dengan menggunakan sembilan blok BMC pada OB.

\section{Bisnis Model OB Awal}

\section{a) Segmen Pelanggan (CS)}

Bisnis yang bergerak dibidang usaha cinderamata yang dilakukan oleh $\mathrm{OB}$ ini, memberikan sasaran pelanggan kepada beberapa jenis pelanggan yang dianggap memerlukan cinderamata untuk berbagai tujuan tertentu. Sasaran pelanggan dari bisnis $\mathrm{OB}$ adalah para turis lokal maupun turis internasional, para pekerja perantauan, penyelenggara dan peserta acara.

\section{b) Proposisi Nilai (VP)}

Proporsi nilai merupakan nilai-nilai yang ditampilkan dari suatu produk yang dapat menjadi faktor ketertarikan pelanggan untuk memilih produk tersebut serta memberikan kepuasan terhadap pelanggan. Bisnis cinderamata yang dilakukan oleh OB ini, memberikan penekanan terhadap nilai ciri khas daerah Banten melalui produk cinderamata. Selain itu juga, OB memberikan harga yang rendah kepada konsumen jika dibandingkan dengan kompetitor - kompetitor yang baru maupun yang lama. Hal tersebut ditujukan agar konsumen dapat memiliki dan menerima produk-produk yang diproduksi oleh OB.

c) Saluran (CH)

Saluran atau channel ini digunakan sebagai media penyampaian, penjualan dan pendistribusian dari proposisi nilai yang telah dimilki perusahaan kepada segmen pelanggan yang dituju. Adapun channel yang digunkan oleh OB melalui dua cara yaitu secara langsung (direct) dan tidak langsung (indirect). Channel langsung melalui gerai $\mathrm{OB}$ dan media berbasis online seperti Google Bisnisku, website, dan social media (facebook, instagram, dan whatsapp). Sedangkan channel tidak langsung meliputi mitra pemasaran ditoko oleh - oleh didaerah Kota Cilegon (Asipa), bookstore Tiga Serangkai (Tisera) dan Rin pin - pin. Bagi konsumen yang memiliki keterbatasan dalam waktu maupun jarak, OB bekerjasama dengan jasa ekspedisi Titipan Kilat (TIKI) dalam pengirman pesanan kepada tangan konsumen.

d) Hubungan Pelanggan (CR)

Bisnis yang dilakukan OB ini, memiliki hubungan terhadap pelanggan termasuk pada jenis transactional, yaitu OB memiliki hubungan dengan konsumen hanya saat melakukan transaksi dilakukan atau dapat dikatakan beli putus. 
Selain itu juga OB memiliki kebijakan terhadap konsumen ketika melakukan transaksi yaitu kebijakan harga atau dapat diartikan kesepakatan harga yang telah dibuat, ketepatan waktu dalam pengiriman barang kepada konsumen didalam pembelian online, adanya refund ketika barang yang tidak sesuai dengan pelanggan serta adanya garansi yang ditawarkan oleh OB. Dengan adanya kebijakan yang telah dibuat oleh $\mathrm{OB}$, diharapkan dapat memberikan nilai lebih kepada konsumen mengenai jaminan produk yang ditawarkan kepada konsumen.

\section{e) Arus Pendapatan (RS)}

Arus pendapatan merupakan cara yang dapat dilakukan untuk mendapatkan pendapatan dalam aktivitas bisnis. Pendapatan yang diperoleh OB yaitu melalui hasil transaksi jual - beli produk cinderamata di OB dan mitra (Asipa, Tisera dan Rin pin - pin) yang melakukan kerja sama dalam penjualan produk OB.

\section{f) Sumber Daya Utama (KR)}

Sumber daya utama merupakan bagian utama yang menjadi kunci dari keberhasilan suatu bisnis. Dalam bisnis cinderamata yang dilakukan OB bagianbagian dari sumber daya utamanya adalah bahan baku, brand yang dapat berfungsi untuk memberikan tanda hak cipta, dan juga intellectual tenaga kerja sebagai pengendali dari fungsi-fungsi aktivitas bisnis.

\section{g) Aktifitas Utama (KA)}

Aktivitas utama didefinisikan sebagai bagian aktivitas terpenting yang dilakukan perusahaan untuk menyampaikan proposisi nilai yang dimiliki. Adapun aktifitas utama yang dilakukan oleh OB adalah mengkonsep desain, memasok bahan baku kepada mitra produksi (UKM), mengawasi dalam produksi (QC), memasarkan dan mendistribusikan proposisi nilai yang dimiliki OB, dan menjalin hubungan terhadap pelanggan.

\section{h) Bangunan Kemitraan (KP)}

Bangunan kemitraan merupakan pihakpihak luar yang dapat menjadi partner untuk bekerjasama dalam bisnis. Tujuan adanya bangunan kemitraan agar dapat memudahkan dalam menjalankan aktivtas bisnis, seperti bekerjasama dalam mengoptimalkan alokasi sumber daya, mengurangi resiko dan ketidak pastian dalam lingkungan persaingan, dan bekerjasama untuk meningkatkan kinerja. Bisnis cinderamata brand $\mathrm{OB}$ ini melakukan pembangunan kemitraan bersamaan penyediaan layanan jasa pengiriman (TIKI), keluarga binaan UKM - UKM yang memiliki kemapuan dalam produksi cinderamat, dan mitra pemasaran OB (Asipa, Tisera dan Rin pin-pin).

\section{i) Struktur Biaya (CS)}

Struktur biaya yang digunakan pada model bisnis cinderamata brand $\mathrm{OB}$ ini adalah gabungan antara pacuan terhadap biaya (cost-driven) dan pacuan terhadap nilai (value-driven) yang diinginkan konsumen yang dituju. Paduan biaya tersebut karena keterbatasan biaya yang dimiliki oleh OB sehingga menyebabkan OB berfokus untuk meminimalisir biaya produksi untuk meningkatkan keuntungan yang diperoleh tanpa mengurangi kualitas dan nilai yang diberikan kepada konsumen. Adapun biaya tetap (fixed-cost) yang dikeluarkan digunakan untuk perawatan terhadap produk-produk yang tersedia dan pembayaran hosting secara rutin pertiap tahunnya. Sedangkan biaya variabel (variable-cost) yang dikeluarkan, digunakan untuk biaya keluarga binaan (UKM) dan bahan baku kerena semua itu disesuaikan dengan jumlah produk yang diproduksi. Gambar dibawah ini merupakan hasil dari identifikasi BMC OB awal yang berjalan saat ini. 


\section{Analisa SWOT}

a) Segmen Pelanggan (CS)

Dalam elemen segmen pelanggan, kekutan pada OB adalah perpindahan pelanggan cukup rendah, pelanggan tersegmentasi dengan tepat dan sering mendapatkan pelanggan baru. Kemungkinan ancaman yang akan muncul adalah terdapat adanya pesaing sejenis. Peluang yang dimiliki adalah mendapatkan manfaat dari pasar yang tumbuh didaerah Banten dan munculnya pelanggan baru yang bergerak dibidang desainer atau perancang pakaian serta mensegmentasikan pelanggan yang dituju agar dapat lebih terfokus kembali.

b) Proposisi Nilai (VP)

Dalam elemen proposisi nilai (VP), kepuasan konsumen menjadi faktor Strengths yang dimiliki OB serta adanya kesinergi yang kuat antara produk dan layanan OB tawarkan kepada konsumen. faktor Weaknesses yang dimiliki adalah Proposisi Nilai OB tidak memiliki dampak jaringan terhadap konsumen yang lainnya. Untuk faktor threats, OB belum merasakan ada acaman hal tersebut karena tersedianya produk yang saling bersubtitusi satu dengan yang lainnya dan harga yang di tawarkan masih bisa bersaing dengan yang lain. Faktor peluang untuk mencukupi kebutuhan pelanggan baru yang sangat menonjol adalah para desainer kostum dan peluang lain yaitu mengadakan kerjasama dengan pihak lain (event organizer, tour and travel, dan toko marcendais, dan lain - lain).

c) Saluran (CH)

Dalam elemen saluran atau channel, OB memiliki kekutan dalam keefisiensian dan keefektifan didalam saluran yang dimilikinya, jangkauan yang kuat terhadap pelanggan, pelanggan dapat melihat saluran yang dimiliki OB serta kesesuaian saluran terhadap segmen pelanggan yang dituju. Kelemahan OB adalah kurangnya maksimal admin dalam penggunaan saluran yang dimiliki. Ancaman saluran dari pesaing untuk sekarang ini masih belum ada karena minimnya usaha sejenis OB di Banten. Peluangnya adalah memaksimalkan saluran - saluran yang ada dan menambah mitra baru agar dapat meningkatkan margin dengan melayani secara langsung serta mampu menyelaraskan saluran dengan segmen pelanggan yang lebih baik lagi.

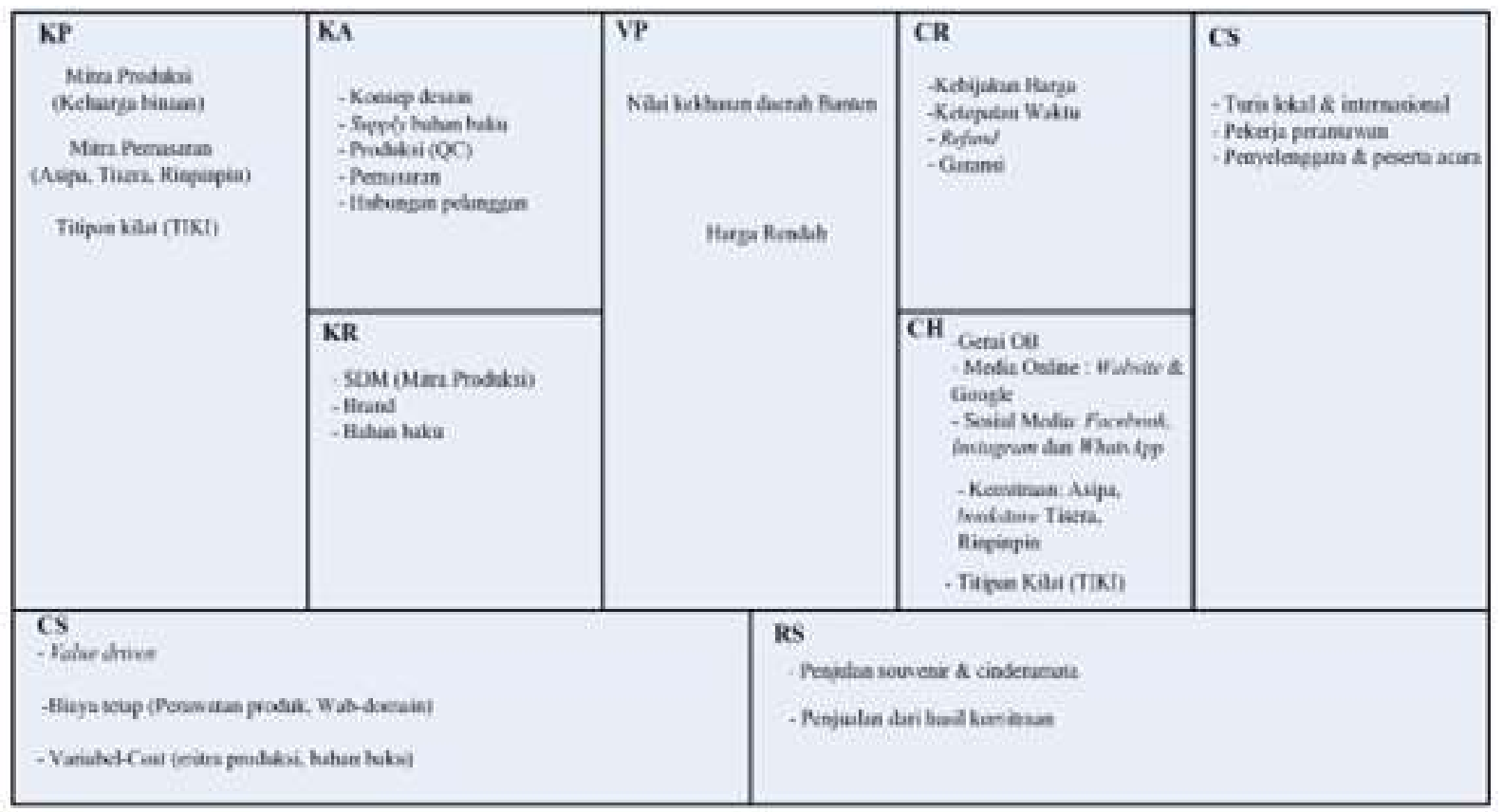

Gambar 5. BMC OB Awal. 


\section{d) Hubungan Pelanggan (CR)}

Dalam hubungan pelanggan, kekuatan yang dimiliki OB adalah cukup kuatnya hubungan terhadap pelanggan yang dimiliki dan kualitas hubungan cukup cocok dengan segmen pelanggan yang dituju. Kekurangannya adalah biaya perpindahan pelanggan sangat rendah, hal tersebut karena OB tidak mengikat pelanggannya dengan sebuah perjanjian. Ancaman hubungan terhadap pelanggan masih belum ada. Peluang yang dimiliki OB untuk meningkatkan kepuasan terhadap pelanggan dengan membuat layanan personal assistance ditujukan untuk mitra pemasaran dan pengaduan konsumen, self-service yang digunakan untuk channel penjualan melalui website dan gerai OB dan customer care yang digunakan sebagai layanan informasi proposisi nilai yang terkandung didalam produk dan pemberian pelatihan terhadap pelanggan.

\section{e) Arus Pendapatan (RS)}

Didalam arus pendapatan, faktor kekuatan yang dimiliki oleh OB adalah memiliki pendapatan diversifikasi, karena memiliki beberapa jaringan sumber pendapatan yang diperoleh. OB mengumpulkan pendapatan sebelum mengeluarkannya serta mengenakan biaya untuk apa yang benar - benar ingin pelanggan bayarkan. Selain itu juga kesesuaian dalam penetapan harga terhadap konsumen. Faktor kelemahannya adalah margin yang diperoleh kecil dan pendapatannya tidak dapat diprediksi. Ancaman terhadap pendapatan masih belum merasakan karena pesaing dari $\mathrm{OB}$ adalah mitra pemasaran $\mathrm{OB}$ sendiri. Peluang yang dimiliki OB adalah terdapatnya penjulana silang baik secara internal ataupun dengan mitra pemasaran serta adanya arus pendapatan lain yang OB ciptakan.

\section{f) Sumber Daya Utama (KR)}

Didalam elemen sumber daya utama, kekuatan yang diunggulkan adalah kemampuan SDM yang sulit ditiru, terutama dalam pembuatan cetakan. Kekurangan yang ada adalah kebutuhan tidak dapat diprediksi terutama produk yang terbuat dari bahan alam. Ancaman pasokan yang dirasakan kemungkinan dapat terganggu terutama dari bahan baku dari alam. Faktor peluang yang dimiliki adalah penggunaan sumber daya yang lebih murah dengan memanfaatkan bahan baku yang ada. Baik dari limbah maupun bahan alam yang lain yang belum tergunakan.

\section{g) Aktifitas Utama (KA)}

Didalam elemen aktivitas utama, kekutan yang dimiliki adalah OB menjalankan aktivitas kunci dengan efisien dan kualitas pelaksanaannya bagus. Kekurangan pada aktivitas utama kemungkinan dapat ditiru karena OB melaksanakan aktivitas tidak sendiri. Ancaman aktifitas utama yang akan dirasakan kemungkinan dapat terganggu disebabkan dari pasokan bahan baku dan kondisi cuaca. Peluang pada aktivitas utama yaitu dengan adanya TI, dapat mendukung peningkatan efisiensi secara umum, baik dalam pemasaran maupun pendistribusian.

\section{h) Bangunan Kemitraan (KP)}

Dalam bangunan kemitraan pada kekuatan yang dimiliki, OB sangat berfokus dan bekerjasama dengan mitra serta menikmati kerjasama tersebut. Karena usaha yang dilakukan OB berbasisi kemitraan pada UKM. Ancaman yang dirasakan, OB adalah tergantung terhadap mitra UKM mulai dari hulu sampai hilir. Peluang yang dimiliki OB adalah dapat melakukan pengalihdayaan pada bagian desainner, pembutan kemasan serta menambah mitra pemasaran untuk pendistribusian produk. Selain itu juga, mitra dapat melengkapi proposisi nilai terhadap OB. 
i) Struktur Biaya (CS)

Dalam elemen struktur biaya, kekuatan yang dimiliki adalah biaya yang dikeluarkan efisien. Untuk kelemahan yang dirasakan, OB masih dapat mensiasati dengan baik mulai dari biaya yang dikeluarkan maupun pembelian bersekala ekonomi. Biaya yang terbesar dalam produksi adalah biaya bahan baku dan itu merupakan salah satu ancaman yang dirasakan oleh $\mathrm{OB}$, namun masih dapat di tanggulangi. Peluang yang dimiliki adalah OB dapat mengurangi biaya terutama dalam hal penggunaan bahan baku.

\section{Evaluasi Blue Ocean}

Pada tahap eliminasi, OB harus mengeliminasi bagian - bagian yang merugikan dalam aktifitas usahanya. Produk cinderamata yang dihasilkan memiliki nilai kearifan lokal yang dibuat secara manual tanpa menggunakan mesin. Seharusnya nilai harga yang ditawarkan dari produk cinderamata sangat tinggi, karena semua itu akan menjadi suatu kebanggan kepada pembeli dalam memiliki produk tersebut. Akan tetapi pemilik usaha lebih menitik beratkan kepada produksi massal dan harga yang terjangkau.

Pada tahap reduce, OB harus mengurangi hubungan dengan konsumen yang memberikan dampak negatif kepada brand OB kedepannya. Hubungan tersebut adalah hubungan dengan konsumen yang ingin menjadi riseller. Pada kasus yang sudah terjadi ada riseller yang membeli produk dengan kapasitas yang banyak, kemudian menjual produk tersebut dengan harga yang melebihi dari batas atas yang telah ditentukan oleh pihak OB. Hal tersebut akan mengakibatkan citra yang buruk terhadap brand kedepannya kepada konsumen - konsumen yang baru.

Pada tahap rise, usaha cinderamata brand OB sudah memiliki media sebagai channels terhadap konsumen baru maupun konsumen lama. OB harus mengelola media sosial secara maksimal sebagai salah satu alat promosi ataupun informasi lainnya.
Selain media sosial, OB memiliki channels tipe yang lain yaitu kemitraan. Mitra penjualan cinderamata OB tidak hanya sebatas daerah Kota Serang dan Cilegon saja. OB juga perlu bekerja sama dengan mitra yang terletak di daerah yang memiliki nilai ekonomi yang tinggi di Provinsi Banten yaitu Kota Tangerang, Kota Tangerang Selatan, Bandara Soekarno-Hatta dan Pelabuhan merak yang menjadi pintu dari wisatawan domestic. Demi meningkatkan kepuasan dari pelanggan serta memahami kebutuhan pelanggan, pihak $\mathrm{OB}$ perlu membuat customer services juga. Peningkatan yang perlu dilakukan oleh pihak OB yang lainnya adalah dengan melalukan komputerisasi data masuk maupun keluar berupa data keuangan dan produk agar pihak OB dapat memantau keuangan dan ketersediaan produk di usahanya.

Pada tahap create, OB perlu menciptakan nilai tambah berupa personal assistance ditujukan untuk melayani mitra pemasaran dan pengaduan konsumen dan layanan pelanggan (customer care) yang berfungsi untuk memberikan pelayanan informasi berupa penjelasan atas nilai yang terkandung dari setiap jenis produk yang diproduksinya, serta penyediakan pelatihan terhadap konsumen yang ingin mencoba untuk membuat souvenir dan cinderamata sendiri dengan bahan yang telah disediakan oleh OB. Penambahan pelayanan terhadap pelanggan yang bernilai tersebut akan menimbulkan rasa kedekatan pihak OB terhadap konsumen begitu juga sebaliknya secara tidak langsung. Pada tahap ini juga, pihak OB dapat menambahkan segmentasi pasar baru yaitu dengan desainer kostom didalan penyediaan haban baku berupa kain tenun dan etnik Banten yang lainnya.

Tahapan create juga dapat dilakukan pada tipe channel yaitu media online (website) yang dimiliki OB saat ini. Dimana produk yang di display pada website adalah produk yang memiliki nilai terhadap kepariwisataan, maka OB dapat memanfaatkan pada halaman depannya untuk dijadikan sebagai jasa informasi periklanan terhadap komponen - komponen 
usaha yang memiliki visi terhadap kepariwisataan dan kegiatan Banten. Keberadaan website tentu juga adanya IT support yang kompeten karena perpengaruh dalam merawat dan menjaga channels tersebut.

\section{Pengembangan Business Model Canvas Baru}

Pengembangan Business Model Canvas Baru terbentuk dari sembilan elemen yang masing-masing memuat hasil dari analisis SWOT dan blue ocean. Pada elemen segmentasi pelanggan merupakan bagian dari pasar yang ingin dituju dan dilayani kebutuhannya dengan produk yang ditawarkan. Segmentasi pasar yang dijadikan target dalam produk yang dihasilkan oleh OB sekarang adalah para turis lokal dan luar negara, pekerja perantauan, penyelenggara maupun peserta acara baik didalam provinsi Banten maupun diluar provinsi Banten serta para desainer kostum pakaian. Produk yang dihasilkan semuanya ditujukan untuk laki laki dan pria dari segala jenis usia.

Pada elemen proposisi nilai yang akan dijadikan value serta kekuatan dari produk OB yang dihasilkannya yaitu nilai kekhasan daerah Banten yang diangkat melalui media souvenir dan cinderamata. Adapun bentuk souvenir dan cinderamata tersebut tertuang didalam souvenir Banten, oblong Banten, etnik Banten dan tenun Baduy. Nilai kekhasan daerah yang dijadikan sebagai proporsi nilai yang ditawarkan oleh OB, akan menjadi nilai tersendiri serta memiliki keunggulan dari kompetitor yang lainnya. Dengan adanya ciri khas daerah yang terkandung dalam setiap produk yang ditawarkan oleh OB, maka akan mempengaruhi dan terbangun persepsi terhadap konsumen mulai dari opini dan kesan mengenai daerah Banten.

Pada elemen channel yang dimiliki oleh OB sudah cukup lengkap, mulai dari penjulan secara langsung (direct) dan tidak langsung / mitra (indirect) hanya butuh dimaksimalkan kembali dalam penggunaannya. Dalam proses penjualan tidak langsung (indirect), OB bekerjasama dengan mitra pemasaran yang sudah ada (Asipa, Tisera \& Rin pinpin). Setelah melakukan analisis, maka perlu ditingkatkan kembali secara fungsinya dan menambah mitra pemasaran baru yang berada dititik tempat yang berpotensi (bandara Soekarno Hatta, pelabuhan Merak, dipusat kota Tangerang dan kota Tangerang Selatan serta). Pada proses penjualan langsung (direct), OB menggunakan media gerai dan online (website, media sosial dan Google) yang dimilikinya. Bagi konsumen yang bertransaksi secara online, OB bekerjasama dengan mitra ekspedisi Titipan Kilat (Tiki) agar produk dipesan sampai ke tangan konsumen sesuai dengan waktu. Dengan adanya website, $\mathrm{OB}$ akan mendapatkan peluang tambahan yang lain yaitu melalui penyediaan jasa periklanan kegiatan daerah Provinsi Banten yang ditempatkan pada website (www. OreBae.com).

Pada elemen customer relationship yang sesuai dengan layanan OB terbagi menjadi dua bagian, yaitu sebagai berikut :

1. Personal assistance yang digunakan untuk mitra pemasaran OB dan untuk menanggapi terhadap keluhan konsumen didalam pembeliannya.

2. Tipe self-service yang digunakan untuk channel penjualan melalui website dan gerai OB. Dimana konsumen dapat memilih sendiri sesuai dengan keinginannya dan memasukkannya pada keranjang belanjaan didasari atas informasi yang tersedia dari setiap produk yang dipilih.

Selain itu juga layanan customer relationship untuk pendekatan $\mathrm{OB}$ terhadap konsumen yang akan dibangun, yaitu berupa layanan pelanggan (customer care) yang berfungsi untuk memberikan pelayanan informasi berupa penjelasan atas nilai yang terkandung dari setiap jenis produk yang diproduksinya, serta penyediakan pelatihan terhadap konsumen yang ingin mencoba untuk membuat souvenir dan cinderamata sendiri dengan bahan yang telah disediakan didalam gerai OB. 
Pada elemen revenue stream yang akan diperoleh melalui penjualan asset dan jasa. Dimana OB untuk menghasilkan pendapatannya melalui penjualan aset berupa produk yang memiliki nilai kekhasan daerah, yang dijual secara langsung maupun bermitra yang berarea di daerah kota Serang dan kota Cilegon. Untuk menambahkan arus pendapatan agar lebih baik lagi, maka OB perlu menambahkan mitra pemasaran pada titik - titik strategis (bandara Soekarno Hatta dan pelabuhan Merak), serta didaerah yang memiliki potensi perekonomian tinggi seperti kota Tangerang dan Kota Tangerang Selatan. Selain itu juga, pendapatan tambahan dari jasa periklanan, dengan menyediakan jasa periklanan pihak lain didalam konten website yaitu www.OreBae.com yang telah disediakan.

Sumber daya utama atau key resources merupakan kunci dalam menjalankan usaha. Sumber daya sendiri terdiri dari 4 macam yaitu physical, intellectual, human dan financial. Pada OB key resources physical adalah kain, cat sablon dan cairan kimia (resin).

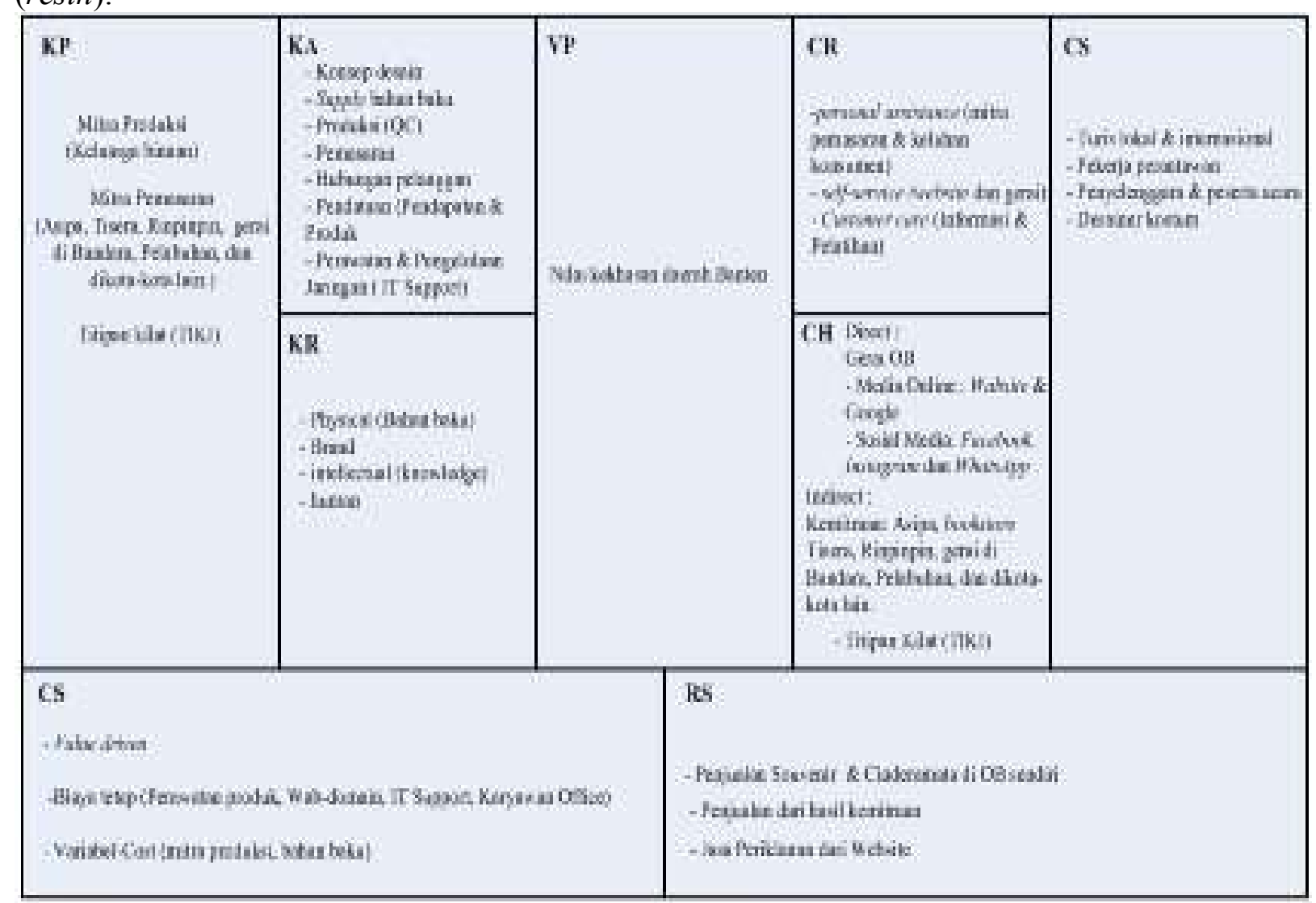

Gambar 6. Pengembangan BMC Baru.
Pada key resources intellectual adalah branding, standar quality control produk, konsep dan desain produk serta it support yang dibutuhkan untuk mengelola dan merawat website. Pada key resources human adalah para pengrajin dan pelaku UKM yang menciptakan produk yang memiliki nilai kekhasan daerah Banten.

Dalam elemen aktivitas utama, aktivitas yang ada sekarang adalah desaining, supplay bahan baku, QC dan packaging, pendistribusian (pemasaran) dan menjalin hubungan terhadap pelanggan. Adapun aktivitas tambahan yaitu aktivitas pendataan terhadap pendapatan, biaya dan produk yang masih tersedia dengan dibantu sistem komputerisasi. Selain itu juga aktivitas tambahan lainnya adalah perawatan dan pengelolaan jaringan (channel) yang dimiliki OB dengan didukung adanya SDM yang memiliki kemampuan dibidang IT support. Aktivitas tersebut digunakan untuk memberikan informasi yang terbaru terhadap pelanggan atas ketersediaan produk dan informasi lainnya. 
Pada elemen kemitraan yang dilakukan oleh pihak OB masih seperti yang sebelumnya yaitu aliansi strategis terhadap usaha kecil menengah (UKM) yang dibina oleh OB, jasa ekspedisi titipan kilat (Tiki), serta mitra - mitra pemasaran (Asipa, Tisera, Rin Pin - Pin). Adapun tambahan yaitu pada mitra pemasaran yang ditujukan pada area bandara, pelabuhan serta di kota-kota yang memiliki potensi besar yaitu di Kota Tangerang dan Kota Tangerang Selatan.

Didalam struktur biaya yang dikeluarkan oleh OB untuk mengoperasikan model bisnisnya yaitu penggabungan antara struktur yang terpacu dalam biaya dan nilai. Hal tersebut disebabkan karena untuk meningkatkan nilai jual tanpa mengurangi kualitas dan menggunakan biaya yang seminimal mungkin. Sedangkan biaya yang dikeluarkan oleh $\mathrm{OB}$ adalah adalah biaya tetap berupa biaya perawatan produk, biaya domain, karyawan office. Sedangkan biaya variabel berupa gaji karyawan (mitra UKM keluarga binaan) dan biaya bahan baku yang disesuaikan dengan total produk yang dipesan konsumen.

\section{KESIMPULAN DAN SARAN \\ 4.1. Kesimpulan}

Dari hasil penelitian yang diperoleh model bisnis Souvenir dan Cinderamata Banten brand Ore Bae agar sesuai dengan kondisi sekarang, maka dibutuhkan perbaikan dari model bisnis awal dengan menambah segmen pelanggan baru berupa desainer kostum, menghilangkan komponen harga murah pada proposisi nilai yang ditawarkan, menambah saluran distribusi produk dititik - titik tempat berpotensi (bandara Soekarno-Hatta, pusat Kota Tangerang, pusat Kota Tangerang Selatan, dan pelabuhan Merak), memaksimalkan fungsi saluran yang sudah tersedia baik secara direct dan indirect yang bersifat online maupun offline serta menambah event Banten pada website Ore Bae sebagai jasa periklanan.
Hal tersebut didukung dengan penambahan sumberdaya utama yang memiliki kemampuan dibidang IT support untuk mengelola dan merawat saluran berbasis online serta jaringan didalam administrasi. Dalam menjalin hubungan terhadap pelanggan, maka diperlukan pelayanan tambahan berupa personal assistance dan customer care yang digunakan sebagai layanan informasi proposisi nilai yang terkandung didalam produk dan pemberian pelatihan terhadap pelanggan. Dari inovasi model bisnis baru ini, diharapkan dapat memberikan manfaat lebih dari model bisnis yang lama.

\subsection{Saran}

Bagi usaha souvenir dan cinderamata Banten brand OB. Diharapkan OB dapata memenuhi kebutuhan segmen pelanggan baru (desainer kostum), memanfaatkan semaksimal mungkin saluran yang sudah dimiliki, menyediakan SDM yang bergerak di bidang IT support. Bagi akademisi, penelitian berikutnya dapat melakukan penelitian tentang seberapa besar pengaruh model bisnis yang terbaru OB terhadap omset pendapatan yang diperoleh. 


\section{DAFTAR PUSTAKA}

Angulo-Guerrero, M. J., Pérez-Moreno, S., \& Abad-Guerrero, I. M., 2017. How Economic Freedom Affects Opportunity And Necessity Entrepreneurship In The OECD Countries. Journal of Business Research, 73, 30-37. https://doi.org/10.1016/j.jbusres. 20 16.11.017.

Budi, I., Bhayangkara, W. D., \& Fadah, I. , 2016. Identification of Problems and Strategies of the Home-Based Industry in Jember Regency. Agriculture and Agricultural Science Procedia, 9, 363-370. https://doi.org/10.1016/j.aaspro.20 16.02.151.

Curry, J. A., Donker, H., \& Michel, P., 2016. Social Entrepreneurship And Indigenous People. Journal of CoOperative Organization and Management, 4(2), 108-115. https://doi.org/10.1016/j.jcom.2016. 09.002 .

Díaz-Díaz, R., Muñoz, L., \& PérezGonzález, D., 2017. Business model analysis of public services operating in the smart city ecosystem : The case of SmartSantander. Future Generation Computer Systems. https://doi.org/10.1016/j.future.201 7.01.032.

DISBUDPAR., 2013. Dinas Kebudayaan Dan Pariwisata Provinsi Banten Tahun 2013. Banten. Retrieved from

http://disbudpar.bantenprov.go.id/u pload/article-pdf/LPPD-2013.pdf.
Ensiklopedia., 2017. Cendera mata. Retrieved from https://id.wikipedia.org/wiki/Cender a mata.

Gabriel, C. A., \& Kirkwood, J., 2016. Business models for model businesses: Lessons from renewable energy entrepreneurs in developing countries. Energy Policy, 95, 336349.

https://doi.org/10.1016/j.enpol.2016 .05 .006 .

Gunardi, G., 2010. Identifikasi Potensi Kawasan Wisata Kali Pasir, Kota Tangerang. Jurnal PLANESA, 1(1), 28-35.

Immaniar, D., \& Ningrum, D. A., 2014. ENRICHING MEDIA MERCHANDISE SARANA PENUNJANG PROMOSI STUDI KASUS PADA BOOK-, 7(40), 420-436.

Jurič, B., \& Vuković, D., 2010. Analysis and Promotion of The Tourist. Tourism \& Hospitality Management 2010, (pp. pp. 1457-1484). Croatia.

Kim, W. C., \& Mauborgne, R., 2005. Blue ocean strategy. California Management Review, 47(3), 105121.

https://doi.org/10.4018/jabim.20100 10104.

Martikainen, A., Niemi, P., \& Pekkanen, P. (2014). Developing A Service Offering for A Logistical Service Provider-Case of Local Food Supply Chain. International Journal of Production Economics, 157(1), 318-326.

https://doi.org/10.1016/j.ijpe.2013.0 5.026. 
Meilia, R., 2013. Rencana Peningkatan Nilai Jual Salak Melalui Pendekatan Nine Building Blocks Sebagai Implementasi Social Entrepreneurship (Studi Kasus: Komunitas Petani Salak Turi Sleman,Daerah Istimewa Yogyakarta). di Yogyakarta: MM UGM.

Mlecnik, E., Kondratenko, I., Cré, J., Vrijders, J., Degraeve, P., Van Der Have, J. A., Paiho, S., 2012. Collaboration Opportunities In Advanced Housing Renovation. Energy Procedia, 30, 1380-1389. https://doi.org/10.1016/j.egypro.20 12.11.152.

Osterwalder, A., \& Pigneur, Y., 2015. Business Model Generation. Jakarta: PT. Elex Media Komputindo.

Osterwalder, A., Pigneur, Y., Smith, A., \& Movement, T., 2010. You 're holding a handbook for visionaries , game changers, and challengers striving to defy outmoded business models and design tomorrow' $s$ enterprises. It's a book for the ... written by co-created by designed by Books google com (Vol. 30). https://doi.org/10.1523/JNEUROSC I.0307-10.2010.

Paraskevaidis, P., \& Andriotis, K., 2015. Values of souvenirs as commodities. Tourism Management, 48, 1-10. https://doi.org/10.1016/j.tourman.2 014.10.014.

Schumpeter, J. A., 1934. The theory of economic development: an inquiry into profits, capital, credit, interest, and the business cycle. Harvard Economic Studies, 46(2), xii, 255. https://doi.org/10.2307/1812657.
Setyawan, B., 2015. Kajian Ekonomi dan Keuangan Regional Provinsi Banten Triwulan III 2015. Banten. Retrieved from http://www.bi.go.id/id/publikasi/kaji an-ekonomi regional/ banten/ Documents/ Kajian Ekonomi dan Keuangan Regional Provinsi Banten Triwulan III 2015.pdf.

Sulistyo, H., \& Siyamtinah., 2016. Innovation capability of \{SMEs\} through entrepreneurship, marketing capability, relational capital and empowerment. Asia Pacific Management Review. https://doi.org/http://dx.doi.org/10. 1016/j.apmrv.2016.02.002.

Swanson, K. K., \& Timothy, D. J., 2012. Souvenirs: Icons of meaning, commercialization and commoditization. Tourism Management. Elsevier Ltd. https://doi.org/10.1016/j.tourman.2 011.10.007.

Tjitradi, E. C., 2015. Evaluasi Dan Perancangan Model Bisnis Berdasarkan Business Model Canvas, 3(1), 8-16.

Trimi, S., \& Berbegal-Mirabent, J., 2012. Business Model Innovation in Entrepreneurship. International Entrepreneurship and Management Journal, 8(4), 449-465. https://doi.org/10.1007/s11365012-0234-3.

Trinh, T. T., Ryan, C., \& Cave, J., 2014. Souvenir sellers and perceptions of authenticity - The retailers of Hôi An, Vietnam. Tourism Management, 45, 275-283. https://doi.org/10.1016/j.tourman.2 014.05.005. 
Wennekers, Sander; Thurik, R., 1999. Linking Enterpreneurship and Economic Growth. Small Business Economics, 13, 27-55. https://doi.org/10.1023/A:10080632 00484.

Wiesner, S., Padrock, P., \& Thoben, K.-D., 2014. Extended Product Business Model Development in Four Manufacturing Case Studies. Procedia CIRP, 16, 110-115. https://doi.org/http://dx.doi.org/10. 1016/j.procir.2014.01.014.

Xing, K., \& Ness, D., 2016. Transition to Product-Service Systems : Principles and Business Model. Procedia CIRP, 47, 525-530. https://doi.org/10.1016/j.procir.201 6.03.236.

Zhang, X., Ma, X., Wang, Y., Li, X., \& Huo, D., 2016. What drives the internationalization of Chinese SMEs? The joint effects of international entrepreneurship characteristics, network ties, and firm ownership. International Business Review, 25(2), 522-534. https://doi.org/10.1016/j.ibusrev.20 15.09.001. 